\title{
Thermochemical Properties and Regularities of Amides, Anilides, and Amidic Acids
}

\author{
Alma Kairlapovna Ryskaliyeva, ${ }^{\star}$ Murat Ergalievich Baltabayev and \\ Aigul Moldakhmetovna Zhubatova
}

\author{
Kazakh National Agrarian University, 8 Abay Av., 050000 Almaty, Kazakhstan \\ *Corresponding author: E-mail: aryskalieva@mail.ru
}

Received: 08-07-2017

\begin{abstract}
The thermodynamic properties of carbamide and its alkyl substituted were studied insufficiently. In this article, the enthalpies of combustion of $\Delta_{c} \mathrm{H}$ of some amides, anilides and amidic acids have been determined experimentally; their standard enthalpies of formation have been calculated. Linear dependences between the average atomic enthalpy of combustion of $\Delta \mathrm{cH}$ amides and their basicity constants in acidic aqueous solutions of $\mathrm{pK}_{\mathrm{BH}}{ }^{+}$have been established; a correlation that relates the enthalpies of combustion of amides and the corresponding amidic acids has been found.
\end{abstract}

Keywords: Enthalpy of combustion, thermochemistry, amides, correlation analysis

\section{Introduction}

Amides, anilides and their derivatives play an important role in various biochemical processes and are therefore widely used as analytical and organic reagents in plant growing, animal husbandry, and pharmacology. Despite the broad practical application, thermochemical properties of carbamide and its alkyl substituted were studied insufficiently. ${ }^{1-3}$ Recently, along with experimental methods of studying thermochemical properties, the methods of establishing empirical correlations based on the application of regression and correlation analyses of thermochemical data are rapidly developing.

In this paper, the results of the experiments carried out by the method of bomb calorimetry to determine the enthalpies of combustion of 11 amides, 5 anilides, and 8 amidic acids and calculate their standard enthalpies of formation are presented. The original methods for calculating the intensive values of enthalpies of combustion as well as empirical correlations linking the intensive values of the enthalpies of combustion of amides and amidic acids are found.

\section{Experimental}

An industrial calorimeter B-08-MA (manufacturer: JSC "Almatinskiy zavod Etalon", the Republic of Kazakhstan, Almaty) with an isothermal jacket and a stationary self-packing calorimetric bomb $\left(\mathrm{V}_{\text {int }}=325 \mathrm{~cm}^{3}\right)$, equipped with two valves (for input and output of gases), was used to determine the enthalpies of combustion of the studied compounds. The measurement error of the calorimeter was $\pm 0.1 \%$, which was absolutely insufficient to make precise measurements. Therefore, in order to improve the accuracy of the determination of the energy of combustion of substances, we, in collaboration with the scientists of the Scientific Research Institute of Physico-Chemical Problems of the Belarusian State University, Minsk, have refined the following parts: the jacket thermostating system, the oxygen purification system, the samples ignition system, the calorimetric vessel, and the calorimetric bomb. As a result, the implemented improvement of the calorimeter made it possible to increase the accuracy of obtained thermochemical values to $\pm 0.01 \%$.

Benzoic acid, which is used in calorimetry as an energy reference, must have a very high purity. We used reference benzoic acid K-1, produced by D. I. Mendeleyev Institute for Metrology (VNIIM), St. Petersburg, which had a purity of $99.997 \mathrm{~mol} \%{ }^{4}$ Also, benzoic acid produced by the National Institute of Standards and Technology of the United States was used as a calorimetric standard; according to the certificate, its purity was $99.997 \mathrm{~mol} \%$, and moisture content - about $0.002 \%{ }^{5}$

The test samples of amides, anilides, and amidic acids were burned as tablets without or with a special polyethylene film which served as an auxiliary substance. In 
the experiment, industrial amides and anilides of "pure" quality were used. They were initially purified with help of several recrystallization stages from a water-ethanol mixture and absolute alcohol. After that, they were purified by sublimation in a vacuum and then stored in a desiccator over phosphorus pentoxide until a constant mass. Amides, synthesized at the Department of Inorganic Chemistry of Al-Farabi Kazakh National University, were purified by recrystallization from water and ethyl alcohol. The content of the main component in the combustion objects was $\sim 99.80 \%$. This was established by the results of elemental and gravimetric (Rossini's method) ${ }^{6}$ analyses.

The masses of combustible samples and polyethylene were determined on microbalances with an accuracy of \pm $2 \cdot 10^{-5} \mathrm{~g}$. Moreover, the amount of substance was chosen in such a way so that the temperature rise in the experiment corresponded to the temperature rise when the reference substance was burned. ${ }^{7}$

After the completion of the experiment, the combustion gases were analyzed for $\mathrm{CO}_{2}$ content by the Rossini method (accuracy $\pm 0.05 \%$ ). The analysis for CO content was carried out with help of indicator tubes (sensitivity $\left.6 \cdot 10^{-6} \mathrm{~kg} \mathrm{l}^{-1}\right)$.

The software for processing calorimetric experiments on combustion of the studied substances and determination of the value of enthalpy of combustion was provided by V. V. Simirsky, ${ }^{8}$ the scientist of Belarusian State University.
The enthalpies of combustion $\left(\Delta \mathrm{H}^{0}\right)$ and the calculated values of the formation enthalpies $\left(\Delta_{\mathrm{f}} \mathrm{H}^{0}\right)$ for all the amides, anilides and amide acids studied by us are presented in Table 1.

\section{Results and Discussion}

Empirical correlations are widespread in all sections of chemistry; they allow us to quantitatively describe chemical processes, to systematize facts and to carry out calculations. One efficient way of establishing quantitative empirical correlations is to transform extensive values into intensive ones, since the latter describe the properties of chemicals more adequately.

The thermodynamic characteristics of a solid matter referred to one mole of structural units and expressed in a stoichiometric gross formula are given in reference books. However, reference thermodynamic values do not allow comparing even the same solid matters which participate in the same chemical processes. Therefore, Kh. K. Ospanov ${ }^{9}$ used average atomic thermodynamic characteristics to describe the differences in the reactivity of solids of the same type such as natural oxides, sulphides, and silicates in homogeneous chemical processes. The simplicity of Ospanov's method of transforming extensive values into intensive ones is striking. For instance, the average atomic enthalpy of combustion of carbamide,

Table 1. Standard enthalpies of combustion and formation of amides and their derivatives

\begin{tabular}{|c|c|c|}
\hline Compound & $-\Delta \mathrm{cH}^{0}, \mathrm{~kJ} \mathrm{~mol}^{-1}$ & $-\Delta_{\mathrm{f}} \mathrm{H}^{0}, \mathrm{~kJ} \mathrm{~mol}^{-1}$ \\
\hline N, N-methylacetylcarbamide & $2154.32 \pm 2.28$ & $563.10 \pm 2.28$ \\
\hline Oxamide & $851.70 \pm 2.27$ & $507.01 \pm 2.27$ \\
\hline a-cyanoacetamide & $1565.43 \pm 2.52$ & $186.80 \pm 2.52$ \\
\hline $\mathrm{N}, \mathrm{N}$-dimethylacetamide & $2598.04 \pm 37.41$ & $282.30 \pm 37.41$ \\
\hline a-phenylacetamide & $4210.40 \pm 3.79$ & $224.02 \pm 3.79$ \\
\hline Propionamide & $3550.10 \pm 0.82$ & $291.37 \pm 0.82$ \\
\hline Valeramide & $3140.62 \pm 0.84$ & $329.04 \pm 0.84$ \\
\hline Isovaleramide & $3149.68 \pm 1.73$ & $390.02 \pm 1.73$ \\
\hline Salicylamide & $3352.32 \pm 2.21$ & $402.68 \pm 2.21$ \\
\hline Nicotinamide & $3083.78 \pm 1.69$ & $131.85 \pm 1.69$ \\
\hline $\mathrm{N}, \mathrm{N}$-dimethylbenzamide & $4959.91 \pm 1.02$ & $153.87 \pm 1.02$ \\
\hline Formanilide & $3591.40 \pm 1.72$ & $177.23 \pm 1.72$ \\
\hline 2,4-dimethylacetanilide & $5501.93 \pm 0.83$ & $291.20 \pm 0.83$ \\
\hline P-aminoacetanilide & $4341.30 \pm 2.28$ & $267.10 \pm 2.28$ \\
\hline Benzanilide & $6576.05 \pm 4.68$ & $111.80 \pm 4.68$ \\
\hline Salicylicanilide & $6379.64 \pm 3.01$ & $308.21 \pm 3.01$ \\
\hline Carbamide nitrate (2: 1) & $1095.48 \pm 1.88$ & $977.82 \pm 1.88$ \\
\hline Biuret Nitrate (1:1) & $881.73 \pm 4.74$ & $762.83 \pm 4.74$ \\
\hline Nitrate oxamide (1: 1$)$ & $1315.24 \pm 2.09$ & $186.39 \pm 2.09$ \\
\hline$\alpha$-cyanoacetamide nitrate $(1: 1)$ & $2304.01 \pm 2.86$ & $408.86 \pm 2.86$ \\
\hline Nitrate propionamide (6: 1) & $12309.66 \pm 4.83$ & $908.06 \pm 4.83$ \\
\hline Valeramide nitrate $(6: 1)$ & $19586.59 \pm 15.07$ & $1784.51 \pm 15.07$ \\
\hline Nitrate isovaleramide (6: 1) & $20287.65 \pm 18.96$ & $1093.45 \pm 18.96$ \\
\hline Nicotinamide nitrate (1: 1$)$ & $2949.05 \pm 4.78$ & $412.49 \pm 4.78$ \\
\hline
\end{tabular}


which equals to $79.01 \mathrm{~kJ} /(\mathrm{g}$-atom), is the molar enthalpy of combustion of carbamide $632.08 \mathrm{~kJ} \mathrm{~mol}^{-1}$ divided by 8 atoms (since the gross formula of carbamide $\mathrm{CH}_{4} \mathrm{~N}_{2} \mathrm{O}$ contains one carbon atom, four hydrogen atoms, two nitrogen atoms and one oxygen atom - total 8 atoms). This is a thermodynamic characteristic of a solid matter recalculated by one mole of atoms, in which there are one fraction of carbon, four of hydrogen, two of nitrogen and one of oxygen.

It is known that amides can be considered as bases. According to the Brønsted-Lowry theories, the base strength can be quantitatively described by the exponent of the basicity constant $\mathrm{pK}_{\mathrm{BH}}{ }^{+}$.

We have established almost a linear relationship between the exponent of basicity constant and the average atomic enthalpy of combustion of the studied amides (Table 2). The high correlation coefficient $r=0.992$ between the values considered also allowed us to calculate the linear regression coefficients by the method of least squares and to find the following empirical correlation:

$$
\Delta_{\mathrm{c}} \mathrm{H}=83.72\left(\mathrm{pK}_{\mathrm{BH}}{ }^{+}-1\right) \mathrm{kJ} /(\mathrm{g} \text {-atom })
$$

Table 2. The correlation dependence between the average atomic enthalpy of combustion $\Delta_{c} \mathrm{H}\left(\mathrm{kJ}(\mathrm{g} \text {-atom })^{-1}\right)$ of amides and their basicity constants in acidic aqueous solutions of $\mathrm{pK}_{\mathrm{BH}}{ }^{+}(\mathrm{r}=0.992)$

\begin{tabular}{lcr}
\hline Amide & $-\Delta_{\mathbf{c}} \mathbf{H}, \mathbf{k J}(\mathbf{g} \text {-atom })^{-\mathbf{1}}$ & $\mathbf{p K}_{\mathrm{BH}}{ }^{+}$ \\
\hline Carbamide & 79.01 & 0.05 \\
Acetamide & 131.78 & -0.62 \\
a-phenylacetamide & 204.39 & -1.30 \\
Phenylcarbamide & 203.69 & -1.30 \\
Benzamide & 221.88 & -1.74 \\
\hline
\end{tabular}

Based on this correlation (1), the following series of changes of the basicity of the amides can be proposed: carbamide $>$ acetamide $>\alpha$-cyanacetamide $>$ valeramide $>$ isovaleramide $>$ nicotinamide $>$ salicylamide $>a$-phenylacetamide $>\mathrm{N}, \mathrm{N}$-dimethylbenzamide.

Thus, correlation (1) can become one of the ways of estimation the enthalpies of combustion $\Delta_{c} H$ of unexplored amides.
The next method of transformation of combustion enthalpies is based on the stoichiometric balance of the combustion reaction equation. For example, the more carbon and hydrogen in the compound formula, the more carbon dioxide and water will be generated as a result of combustion, the more oxygen is required for combustion and the greater the numerical value of the combustion enthalpies. This proposition underlies A. A Ravdel's equation: ${ }^{10}$

$$
-\Delta_{c} H=204.2 n+44.4 m+\Sigma x_{i}
$$

where,

$\mathrm{n}$ - the number of oxygen atoms required for the combustion of one mole of the substance;

$\mathrm{m}$ - the number of water molecules formed;

$\Sigma \mathrm{x}_{\mathrm{i}}$ - additive correction (thermal characteristic of the same type of substances).

The parameters of Ravdel's equation ( $\mathrm{n}$ and $\mathrm{m}$ ) reflect the balance of oxygen and water in the combustion reaction equation. These are parameters of the extensiveness of the combustion process. Therefore, the value of the enthalpy of combustion divided by the sum of the parameters of Ravdel's equation $(n+m)$ should serve as an intensive value that can have a correlation with the physico-chemical properties of the substance being burnt. For example, complete combustion of one mole of carbamide requires three moles of oxygen and, as a result, two moles of water are formed; therefore $n+m=5$. Consequently, the enthalpy of combustion of carbamide normalized by the oxygen-water balance will have the following quantitative value:

$$
\left(\frac{\Delta c H}{n+m}\right)=\frac{632.06}{3+2}=126.41 \mathrm{~kJ}
$$

A comparison of the normalized values (Table 3 ) of the standard combustion enthalpies of the amides $(\mathrm{A})$ and the corresponding amidic acids (AA) allowed us to establish a linear regression equation with a high correlation coefficient $\mathrm{R}=0.997$ :

$$
\left(\frac{\Delta c H}{n+m}\right)_{\mathrm{AA}}=1.1 \times\left(\frac{\Delta c H}{n+m}\right)_{\mathrm{A}}
$$

Table 3. The relationship between the normalized values of the enthalpies of combustion of amides and their corresponding amidic acids (nitrates)

\begin{tabular}{lclcc}
\hline Amide (A) & $-\frac{\Delta_{\mathrm{c}} \mathrm{H}}{\mathrm{n}+\mathrm{m}}$ & Amidic acids (AA) & $-\frac{\Delta_{\mathrm{c}} \mathrm{H}}{\mathrm{n}+\mathrm{m}}$ & $\boldsymbol{\varepsilon}, \boldsymbol{\%}$ \\
\hline carbamide & 126.4 & carbamide nitrate $1: 1$ & 136.9 & 1.6 \\
valeramide & 157.3 & valeramide nitrate 6:1 & 166.0 & 4.2 \\
a -cyanoacetamide & 173.9 & cyanoacetamide nitrate $1: 1$ & 200.4 & 0.7 \\
nicotinamide & 181.4 & nicotinamide nitrate & 196.6 & -4.5 \\
oxamide & 276.8 & oxamide nitrate & 328.8 & 7.4 \\
\hline
\end{tabular}


The relative deviation of the experimental values of $\left(\frac{\Delta c H}{n+m}\right)_{\text {AA }}$ from correlation (2) does not exceed 7.4\%, which is the generally accepted accuracy ( $10 \%)$ for Lauthier-Karapet'yants correlations. ${ }^{11}$ Thus, correlation (2) can be used for computational determination of enthalpies of combustion of amidic acids, which have been not yet studied in thermochemistry, applying the thermochemical characteristics of the corresponding amides.

\section{Conclusion}

By the method of bomb calorimetry, the enthalpies of combustion $\Delta_{\mathrm{c}} \mathrm{H}$ of 11 amides, 5 anilides, and 8 amidic acids were experimentally determined. Their standard enthalpies of formation were calculated. A linear dependence between the average atomic values of the enthalpy of combustion of amides $\Delta_{\mathrm{c}} \mathrm{H}$ and their basicity constants in acidic aqueous solutions $\mathrm{pK}_{\mathrm{BH}}{ }^{+}$was found:

$$
\Delta_{\mathrm{C}} \mathrm{H}=83.72 \times \mathrm{pK}_{\mathrm{BH}}{ }^{+}-83.72
$$

A correlation that relates the normalized values of the enthalpies of combustion of amides and their nitrates was found:

$$
\left(\frac{\Delta c H}{n+m}\right)_{\mathrm{AA}}=1.1\left(\frac{\Delta c H}{n+m}\right)_{\mathrm{A}} .
$$

\section{References}

1. A. K. Ryskalieva, G. V. Abramova, N. N. Nurakhmetov, R. Sh. Erkasov, Russ. J. Phys. Chem. A., 1991, 4, 1068-1070.

2. A. K. Ryskalieva, P. Sh. Erkasov, G. V. Abramova, N. N. Nurakhmetov, Izv. Vyssh. Uchebn. Zaved., Khim. Khim. Tekhnol., 1991, 9, 25-27.

3. A. K. Ryskalieva, G. V. Abramova, R. Sh. Erkasov, N. N. Nurakhmetov, Russ. J. Phys. Chem. A., 1992, 3, 797-799.

4. Yu. I. Aleksandrov, T. R. Osipova, V. F. Yushkevich, in: B. N. Oleinik (Ed): Methods and Means of Calorimetry of Thermophysical Measurements (Metody I Sredstva Kalometrii Teplofizicheskikh Izmereniy) D. I. Mendeleyev Institute for Metrology (VNIIM), St. Petersburg, Russia, 1984, 250 p.

5. Nat. Bur. Stand. Certificate of Analisis, Standard Reference Material 39-I Benzoic Acid, Calorimetric Standard, Washington: D. C., 1968, №20234. -pp. 44-59

6. F. D. Rossini Experimental thermochemistry, Interscience Publishers Inc., New York, USA, 1956, 326p.

7. V. P. Kolesov Fundamentals of thermochemistry, SSU, Moscow, Russia, 1996, 204 p.

8. V. V. Simirsky, Ph. D. Thesis, Belarusian State University, Minsk, 1986.

9. Kh. K. Ospanov, General principles of prediction of differences in reactivity of minerals and solvents in the conditions of processing of mineral raw materials, Kazakh University, Almaty, Kazakhstan, 2015, 409 p.

10. Quick Reference of Physico-Chemical Variables, (Ed): A. A Ravdel and A. M. Ponomareva, Chemistry, St. Petersburg, Russia, 1983, 232p.

11. A. K. Ryskalieva, Ph. D. Thesis, Al Farabi Kazakh National University, Almaty, 1998.

\section{Povzetek}

$\mathrm{Z}$ meritvami v bombnem kalorimetru smo določili sežigne entalpije, $\Delta \mathrm{H}$, nekaterih amidov, anilidov in amidnih kislin (nitratov) ter izračunali njihove standardne tvorbene entalpije. Ugotovili smo linearno odvisnost med povprečno $\Delta \mathrm{H}$ in konstantno bazičnosti v kislih vodnih raztopinah, $\mathrm{pK}_{\mathrm{BH}}{ }^{+}$ter postavili zvezo med $\Delta_{\mathrm{c}} \mathrm{H}$ amidov in ustreznih amidinskih kislin (nitratov). 